\title{
Raltegravir switch improves hepatitis $C$ transaminitis in HIV-1 and hepatitis C (HCV) co-infected individuals
}

\author{
Muge Cevik ${ }^{* \dagger}$, Gurmit Singh ${ }^{\dagger}$, Laura Dickinson, Andrew Scourfield, Marta Boffito, Mark Nelson \\ From 17th International Symposium on HIV and Emerging Infectious Diseases (ISHEID) \\ Marseille, France. 23-25 May 2012
}

\section{Introduction}

$\mathrm{HCV}$ is one of the most relevant co-morbidities seen in HIV-infected individuals as evidenced by the negative impact that HIV exerts on the course of HCV infection. Despite remarkable results on HIV infection alone, the impact of highly active antiretroviral therapy (HAART) on liver disease in co-infection remains unknown. We sought to explore the impact of Raltegravir (RAL) on amino transferase (ALT) in HIV/HCV co-infected individuals.

\section{Methods}

HIV-infected individuals co-infected with HCV within the last 5 years receiving non-integrase inhibitor containing HAART with a subsequent switch to RAL-containing HAART were identified from a retrospectively maintained outpatient database. Patient demographics were extracted. Biochemical, virological and immunological parameters were collated and individuals received pegylated interferon with ribavirin were excluded. ALT levels at switch and post switch were compared using Kruskal-Wallis test. Spearman's Rank correlation was used to assess the relationship between ALT and HCV-RNA.

\section{Results}

Twenty seven HIV-HCV co-infected individuals were identified between January 2007 and January 2012 and seven individuals were excluded. Median age was 44 years (range: 31-68). Five had acute and fifteen had chronic HCV infection during the switch. Twenty (100\%) had HIV-RNA-1.

\section{Conclusion}

In our study, RAL had a favourable effect on the liver up to 24 weeks after switch in HIV/HCV infected individuals.

Published: 25 May 2012

doi:10.1186/1742-4690-9-S1-07

Cite this article as: Cevik et al:: Raltegravir switch improves hepatitis C transaminitis in HIV-1 and hepatitis C (HCV) co-infected individuals. Retrovirology 2012 9(Suppl 1):07.

* Correspondence: muge.cevik@chelwest.nhs.uk

† Contributed equally

Chelsea and Westminster Hospital, London, UK

Submit your next manuscript to BioMed Central and take full advantage of:

- Convenient online submission

- Thorough peer review

- No space constraints or color figure charges

- Immediate publication on acceptance

- Inclusion in PubMed, CAS, Scopus and Google Scholar

- Research which is freely available for redistribution
C Biomed Central 